\title{
EXTENSÃO RURAL E INTERDISCIPLINARIDADE: CONSTRUÇÕES DIALÓGICAS
}

\author{
Rosa Cristina Monteiro ${ }^{1}$ \\ Cecilia Moreyra de Figueiredo ${ }^{2}$
}

\begin{abstract}
RESUMO
O presente artigo discute a importância da interdisciplinaridade na extensão rural, destacando a interação com o campo das ciências humanas, em especial a psicossociologia. A interdisciplinaridade é apresentada pelas autoras como uma exigência epistemológica crítica e política. A entrada da psicossociologia é sustentada pela compreensão de que o fenômeno da subjetividade não pode estar ausente dos saberes e fazeres que envolvem o humano e suas relações sociais. Trata-se de um ensaio em que a extensão rural se apresenta como um lugar privilegiado para a pesquisa interdisciplinar, na medida em que reúne ação e reflexão em contextos bem definidos e que incorporou diversas disciplinas na composição de seu corpus atual - as disputas paradigmáticas que se sucederam deixaram um lastro de possibilidades para composições originais, às vezes rivais, mas sempre compatíveis com o cenário das novas diplomacias exigidas pela pósmodernidade. A primeira parte da reflexão, de caráter teórico, se relaciona com a segunda parte que reúne fragmentos de um estudo de campo realizado na Amazônia brasileira no qual já se experimenta uma intersecção disciplinar que se pretende original.
\end{abstract}

Palavras-chave: assistência técnica, complexidade, subjetividade, transição paradigmática.

\section{RURAL EXTENSION AND INTERDISCIPLINARITY : CONSTRUÇÕES DIALOGIC}

\begin{abstract}
This article analyzes the importance of interdisciplinarity in rural extension, highlighting the interaction with the human sciences, especially psychosociology. The interdisciplinary approach is presented by the authors as an epistemological requirement critical and political. The psychosociology aproach is underpinned by the realization that the phenomenon of subjectivity can not be absent from the knowledge and practices involving human and social relationships. This is an essay

\footnotetext{
${ }^{1}$ Graduada em Psicologia. Mestrado em Psicologia Social (FVG/RJ). Doutorado em Ciências Sociais (CPDAUFRRJ); Professora adjunta da Universidade Federal Rural do Rio de Janeiro (UFRRJ). E-mail: rosacristina.monteiro@gmail.com

${ }^{2}$ Graduada em Comunicação Social (PUC/RJ). Especialista em Fotografia como Instrumento de Pesquisa em Ciências Socias (UCAM). Mestrado em Ciências Socias (UERJ). Doutoranda em Psicossociologia (EICOS/UFRJ). Professora Assistente na Universidade Federal Rural do Rio de Janeiro (UFRRJ). E-mail: cissafig@gmail.com
} 
in which the rural extension appears as a privileged place for interdisciplinary research, in that it brings together action and reflection on well-defined contexts and that incorporates various disciplines in the composition of its current corpus - the paradigmatic disputes ensued possibilities for original compositions, sometimes rivals, but always consistent with the scenario of the new diplomacy required by postmodernity. The first part of reflection, being a theoreticalone, relates to the second part that brings together fragments of a field study conducted in the Brazilian Amazon in which experiences of disciplinary intersection have been done.

Keywords: complexity, paradigmatic transition, subjectivity, technical assistance.

\title{
1. INTRODUÇÃO
}

\begin{abstract}
O que me interessa é o fenômeno multidimensional e não a disciplina que recobre uma dimensão desse fenômeno. Tudo o que é humano é ao mesmo tempo físico, sociológico, econômico, histórico, demográfico; interessa, pois, que esses aspectos não sejam separados, senão concorram para uma 'multivisão'. O que me motiva é a preocupação de ocultar o menos possível a complexidade do real. (BOAVENTURA DE SOUZA SANTOS).
\end{abstract}

O texto que segue enfatiza a importância das construções interdisciplinares no domínio da extensão rural e destaca, a título de exemplo e proposta, a interação com o campo das ciências humanas, em especial a psicossociologia. Afirmar a interdisciplinaridade constitui para nós uma exigência epistemológica crítica e política, que estará exposta ao longo do artigo. Apontar para o domínio da psicossociologia é consequência, por um lado, da nossa própria formação acadêmica e por outro, da nossa compreensão de que o fenômeno da subjetividade não pode estar ausente dos saberes e fazeres que envolvem o humano e suas relações sociais.

Do ponto de vista da teoria do conhecimento, a extensão rural aparece como um lugar privilegiado para a pesquisa interdisciplinar, na medida em que reúne ação e reflexão em contextos bem definidos. Além disso, em seu percurso histórico incorporou diversas disciplinas que contribuíram para formar seu corpus atual - as disputas paradigmáticas que se sucederam deixaram um lastro de possibilidades bastante propício a composições originais, às vezes rivais, mas sempre compatíveis com o cenário das novas diplomacias exigidas pela pós-modernidade.

Trata-se de um ensaio organizado para refletir experiências de intercâmbios institucionais que se alargaram desde um primeiro encontro com o programa de PG em extensão rural da Universidade Federal de Santa Maria, e que chegou hoje a formar um lugar institucional dinâmico, no qual o campo das interações de saberes e práticas se alarga e os encontros se multiplicam fecunda e prazerosamente. A primeira parte de nossa exposição é de caráter teórico, e a segunda parte apresenta fragmentos de um estudo de campo realizado na Amazônia brasileira no qual já se experimenta uma intersecção disciplinar que se pretende original. 


\title{
2. VETORES EPISTEMOLÓGICOS DA EXTENSÃO RURAL: MULTIDISCIPLINARIDADE E INTERDISCIPLINARIDADE
}

É fato sobejamente conhecido que as primeiras intervenções que instituíram o campo da extensão rural no Brasil importavam o modelo norteamericano, que precisou ser adaptado aqui para fazer frente a condições de desigualdade que faziam coexistir riquezas imensas e pobrezas igualmente imensuráveis. As práticas sustentaram-se na implementação de políticas de crédito para viabilizar a base material exigida na chegada de novos arranjos técnicocientíficos, e foram organizadas em torno da imagem do rural como espaço agrícola e do agricultor como um ator social carente de algum tipo de incentivo/estímulo externo para prosperar. O domínio econômico das instituições de financiamento e crédito foi legitimado por um ideário sociopolítico regido pela noção de desenvolvimento.

\begin{abstract}
a noção de desenvolvimento faz parte de um dispositivo político que busca estabelecer uma racionalidade social, classificando e hierarquizando as coletividades humanas, territorialmente definidas, segundo valores gerados e geridos em contextos estranhos a elas mesmas. Desenvolver significa, no plano das ações políticas, fazer com que sociedades consideradas atrasadas evoluam para atingir o nível de outras sociedades (REIS; VIANA; MONTEIRO, 2008, p. 70).
\end{abstract}

Estávamos no pós-guerra e na plena vigência do processo de industrialização marcado pela atuação forte e centralizada do Estado como planejador dos grandes projetos de base territorial. Os caminhos abertos pela Constituição de 1937 (SANTOS, 2010) e a perspectiva de integração nacional pregnante neste período, promoveram o avanço das tecnoestruturas em direção aos territórios rurais e a elaboração de programas de assistência técnica. Neste ponto a extensão rural significava a modernização do campo com a aplicação dos conhecimentos técnicos e científicos da agronomia e da economia, principalmente, formando um arranjo multidisciplinar.

Não sendo nosso propósito aqui repassar a história da extensão rural, pontuamos este momento inaugural para deixar evidente uma primeira raiz epistemológica: tratava-se então da preparação de um campo de saber/fazer no qual a dinâmica das relações de poder já estava bem estabelecida. Tanto no domínio das ciências agrárias, quanto da economia, anunciava-se já uma posição de dependência e subordinação que produziu efeitos profundos. O mundo rural sendo considerado um espaço atrasado, os seus protagonistas sociais não poderiam deixar de ser assim também considerados. Boa parte do território epistêmico das populações locais foi desvalorizado, ocultado ou eliminado na entrada dos vetores desta primeira e incipiente modernização.

Tal crítica epistemológica está bem exposta por Santos (2010) que aponta para a problemática da colonização e seus cortes profundos. Para ele, o colonialismo implicou em um conjunto de intervenções no campo do conhecimento que suprimiram formas de saber próprias dos povos e nações colonizados, não se restringindo assim à dominação econômica, territorial e política do Norte sobre o Sul. Foram também criadas fronteiras no que tange à produção do conhecimento.

Seguindo ainda no rumo inaugurado em 1948, as políticas públicas para o mundo rural intensificaram o processo brasileiro de modernização que acelerou todos os vieses apontados antes: econômicos, científicos, sociais e epistemológicos. 
Os programas de governo e as políticas de Estado, nas décadas de 1960 e 1970, tinham como meta principal a adaptação de tecnologias para modernizar a economia e ajustá-la às novas realidades da economia mundial, e entre outras ações estava o aumento das exportações agrícolas e a modernização do campo. Pontos longínquos do território nacional foram anexados à modernização capitalista:

\begin{abstract}
O país conhece uma ocupação periférica. A decisão geopolítica de estimular a industrialização em diversas regiões e ocupar o território com projetos de colonização teve influência relevante nesse processo, mas o próprio mercado jogou papel fundamental, viabilizado pelas novas infraestruturas de transportes e comunicação, assim como pela superestrutura dos mecanismos reguladores, sob o comando do estado e dos agentes hegemônicos da economia, por meio dos intermediários financeiros (SANTOS, 1993, p. 44).
\end{abstract}

Duas questões epistemológicas acrescentaram-se às anteriores: a total autonomização da técnica em relação à ciência, formando o que Milton Santos chama de paradigma técnico-científico-informacional, e a passagem das ciências sociais, até então mais reflexivas do que intervencionistas, para o domínio de um campo chamado "gestão social", que tecnifica, por último, todas as ações, mesmo as mais imateriais.

Neste cenário foi decisivo o papel dos pesquisadores do Instituto Superior de Estudos Brasileiros (ISEB) do Ministério de Educação, a quem se atribui a formulação de uma ideología nacional/desenvolvimentista; apesar de apresentaremse como impulsionadores de políticas que se pretendiam emancipadoras, adotaram em suas pesquisas e seus encaminhamentos uma concepção de crescimento econômico circunscrito ao urbano/industrial sem qualquer sensibilidade às posturas mais radicais de transformação social que se manifestavam, por exemplo, nas Ligas Camponesas (Iglesias, 1994 apud REIS; VIANA; MONTEIRO, 2008).

Tal modelo de extensão rural, com ênfase no incremento exponencial da produção agrícola, foi abalado por duas críticas principalmente no final do século XX: a problemática do desgaste ambiental provocado pelo crescimento da produção, quando a aplicação técnica torna-se um fim em si mesma, e a radical desumanização das relações socioculturais, promovendo a pobreza, o desemprego, a precarização das condições de vida do trabalhador do campo que migrou para as cidades para sobreviver em condições mais precárias ainda. Constatou-se amplamente o caráter injusto, concentrador e excludente destas práticas, exigindo total revisão e declinação das políticas de extensão rural (MOREIRA, 2003).

Duas imagens do rural surgiram das críticas - espaço da natureza a ser cuidada e preservada, e espaço de significativa interação social. A agenda da extensão rural foi modificada então neste duplo sentido, matizando o protagonismo das ciências sociais, agronômicas e econômicas para abrigar um outro arranjo científico incluindo a ecologia, a pedagogia, a comunicação e a antropologia. Ao serem atravessadas por disciplinas analíticas e críticas, a extensão rural ganhou um aspecto propriamente interdisciplinar, superando a multidisciplinaridade do momento anterior e tornando-se sensível aos exercícios de poder, gerando paradigmas alternativos, com ênfase na participação cidadã.

Em 1987 a Empresa Brasileira de Assistência Técnica e Extensão Rural (EMBRATER) lançou o documento Políticas e Diretrizes de Formação Extensionista no qual define a extensão rural como um processo educativo permanente, caracterizado pela relação e comunicação recíproca e constante dos técnicos com os produtores, suas famílias e suas organizações. Segundo o documento a 
formação extensionista se constitui num processo construtivo de um novo saber para um novo fazer, através de procedimentos de capacitação, supervisão, assessoria e intercâmbios. Neste ponto, as próprias políticas públicas explicitam a dimensão epistemológica de suas ações. ${ }^{3}$

A partir do século XXI adotou-se no Brasil uma outra política de assistência técnica e extensão rural, desta vez no marco de um Estado de corte progressista, quando em 2010 foi sancionada a Lei de ATER, criando a Política Nacional de Assistência Técnica e Extensão Rural para Agricultura Familiar e Reforma Agrária (PNATER) e o Programa Nacional de Assistência Técnica e Extensão Rural na Agricultura Familiar e na Reforma Agrária (PRONATER) (BRANDÃO, 2014).

A criação do Ministério do Desenvolvimento Agrário representou atuação mais significativa na supervisão das políticas que incidem no mundo rural e que visam promover processos de gestão, produção, beneficiamento e comercialização das atividades e dos serviços agropecuários e não agropecuários, inclusive das atividades agroextrativistas, florestais e artesanais, mediante processos educativos e participativos, que assegurem sustentabilidade, cidadania e melhoria na qualidade de vida das populações rurais. Como é de se imaginar, definida assim a extensão rural pode abrigar em seu campo um amplo leque de disciplinas e técnicas, e sem dúvida já há algumas tensões importantes que explicitam mais claramente as relações saber/poder.

No domínio epistemológico, o confronto entre dois conjuntos disciplinares apenas já é suficiente para evidenciar que qualquer proposta de ação implica compromissos sociais: quando se confrontam no mesmo campo os economistas (ou economicistas) e os antropólogos (ou culturalistas) a discussão se agrava. A arena dos debates dicotomiza uma posição que aponta para a urgência em fazer passar os agricultores de um regime de subsistência a um regime de excedentes agrícolas, preocupando-se principalmente com o aumento da produtividade, e outra que aponta os riscos de desaparecimento de um patrimônio simbólico que poderia deixar coletivos inteiros em condições de indigência sociopsíquica, na medida em que corroeria a fortaleza das identidades.

Apesar das novas tensões representarem uma ruptura paradigmática importante, ela mantém dois vieses fortes que estavam já na origem das intervenções no campo: o cientificismo e o desenvolvimentismo. Ambos produzem efeitos de dominação e sujeição (REIS; VIANA; MONTEIRO, 2008). Portanto, uma possível saída deste círculo vicioso, no qual o rural e os sujeitos rurais aparecem em condições de subordinação, implica a adoção de outros métodos e principalmente de outras mentalidades. Trata-se de alterar a percepção e os sentidos dominantes, a favor de outras construções.

Para além das intenções e enquadramentos políticos de cada uma das visões de mundo e do fazer científico, há uma compreensão a respeito dos dispositivos acionados nos processos de apropriação do conhecimento por diferentes grupos e coletividades, que impõe uma reflexão: quando o conhecimento é produzidos a partir dos padrões intelectuais ocidentais modernos, podem produzir um efeito de uniformização e/ou marginalização dos grupos envolvidos nas pesquisas, e acabam por corresponder, inevitavelmente, a exercícios de dominação e opressão ainda mais insidiosos. Queremos evidenciar que certos movimentos que permanecem na superfície dos acontecimentos macropolíticos ou unicamente vinculados à noção hegemônica de globalização, deixam de levar em conta os jogos

\footnotetext{
${ }^{3}$ Note-se que apenas na proposta de intercâmbio a prática extensionista se lateralizou, porque nas outras ações, mantem-se a relação verticalizada entre cientistas, técnicos e agricultores. Esta anotação é importante para pensar a cena atual da extensão rural.
} 
de poderes e contrapoderes que se efetuam nos níveis das interações humanas.

Segundo Santos (2007), é necessário reinventar as ciências sociais no sentido de repensá-la epistemologicamente e superar o que chama de racionalidade indolente, que desperdiça experiências múltiplas ao se considerar a forma exclusiva de abordar determinada situação social e não se exercita o suficiente para ver a riqueza inesgotável do mundo.

Froehlich (2012) chama a atenção para um dos elementos cruciais do cenário contemporâneo quando envolvemos pessoas, e que ele chama de "mobilidade simbólica", matéria prima para a coexistência de identidades múltiplas em um mesmo processo de subjetivação e singularização. Parafraseando Canclini (1995 apud FROEHLICH, 2012), nos diz o autor:

Os indivíduos não pertencem mais a um só grupo ou localidade, e portanto não têm mais uma única identidade distintiva e coerente. As identidades construídas e permeadas pela lógica cultural pós-moderna são híbridas, maleáveis e multiculturais. E como as possibilidades tecnológicas e sociais de nossa época possibilitam aos indivíduos e aos grupos intervir em escalas territoriais múltiplas, essa construção identitária acaba por internalizar, muitas vezes, as contradições (ou os paradoxos) entre as diversas escalas de pertencimento (FROEHLICH, 2012, p. 202).

É com a constatação de que somos múltiplos, e que em nenhum plano as hierarquias têm já consistência, seja no plano epistêmico ou societal, que somos levados a pensar a interdisciplinaridade que queremos em sua expressão de maior complexidade, apresentada por Edgar Morin e bem apropriada por Vasconcelos (2004). Como um contraponto ao "paradigma da simplicidade" Morin (1990) propõe uma abordagem da complexidade pela qual entende um processo de tecer em conjunto elementos que não podem ser separados e que constituem um todo e que ao mesmo tempo representam unidade e multiplicidade. Segundo este autor, a complexidade expõe fenômenos complicados e que necessitam de métodos complexos para serem explicados. Estes fenômenos complexos unem a ordem e a desordem em um processo de interação contínua de forma antagônica e complementar. Fenômenos complexos são marcados por processos de emergência, pelos quais novas propriedades surgem a partir da interação das partes ou dos diferentes níveis de realidade ou organização, marcando a necessidade de diferentes epistemologias para estas abordagens.

Vasconcelos (2004) afirma que, de acordo com o paradigma da complexidade, a produção do conhecimento depende fortemente da experiência sócio-histórica, pessoal e subjetiva dos pesquisadores. O desenvolvimento da criatividade e da inovação nesta esfera se sustenta na capacidade dos pesquisadores assumirem 0 processo de troca permanente entre suas singularidades em diferentes áreas do conhecimento, como um esforço de produzir esta trama complexa proposta por Morin, onde as diferenças emergem e se complementam na solução, análise e abordagem de realidades complexas próprias da pós-modernidade.

\section{COMPLEXIDADE, POLÍTICA E SUBJETIVIDADE}

A epistemologia da complexidade, enquanto paradigma radical da interdisciplinaridade, apresenta para nós um sentido político e um método de ação. Politicamente trata-se da instauração de processos emancipatórios visando 
mudanças nos pontos em que as circunstâncias evidenciam submissão, subordinação e/ou controle. O sentido das mudanças esperadas é o da solidariedade coletiva. Quanto ao método, compreende-se na complexidade que as interferências/intervenções ocorrerão em correspondência com a dimensão da subjetividade, individual e social, isto é, levarão em conta o plano afetivo das relações que se estabelecem no caminho cotidiano das ações.

O lugar dos processos emancipatórios é o lugar do horizonte diário, da reconstrução das relações possíveis; não é o lugar do céu e dos grandes espaços e muito menos do chão imediato; por uma razão muito simples. Estes espaços não existem - o que existe é o lugar. Olhe para a direita, e olhe para a esquerda; pense nas múltiplas conexões entre lugares que formam o seu horizonte de ação. É só isso, nada mais. Em termos analíticos podemos falar dos espaços mezaninos e de médio alcance, mas basicamente estamos falando do lugar onde o local e o global se conectam numa pororoca nada confortável, o lugar que habitamos e as suas possibilidades emancipatórias, porque é só isso o que temos - nada mais (SPINK, 2007, p. 315).

Cada sujeito está integrado de múltiplas formas com o mundo em que vive. $\mathrm{Na}$ dimensão da subjetividade social é preciso admitir que a emancipação social deve corresponder à emancipação do sujeito pessoal, e isto passa pois pela compreensão de que as ações e seus efeitos são produtores de ruptura. O que assegura a possibilidade de ruptura é um processo de sentido, resultante da atividade pensante e reflexiva, constante na experiência humana, e que também pode ser apreendida sob a designação de consciência:

Organização processual na qual o sujeito participa intencionalmente nos processos de sua vida, o que implica a organização de sua própria linguagem, na reflexão, na elaboração de projetos e no momento construtivo de suas filosofias de vida, de suas crenças e suas representações (...) A configuração de sentidos que está na base de cada ação humana única é apreendida de forma total pelo sujeito concreto (REY, 2003, p. 226).

Em sociedades democráticas abertas e flexíveis, em que as contradições podem ser expostas à luz do dia, as subjetividades sociais e o sujeito individual dialogam, tocam-se, sentem um ao outro e emergem reconfigurados. "A linguagem está constituída dentro de um cenário social e individual de forma simultânea, é um momento de subjetividade social e da subjetividade individual, momentos estes que se expressam permanentemente por meio de uma tensão mútua" (REY, 2003, p. 229).

Quando diferentes conhecimentos e saberes incidem sobre um mesmo campo de práticas sociais, como no caso da extensão rural no Brasil contemporâneo, os significados sociais produzidos em cada um deles capturam a consciência social em uma ou outra direção: várias figuras e papéis sociais se superpõem e tensionam a elaboração e gestão de programas e políticas públicas. $E$ não apenas os conflitos sociais são importantes. Há que se reconhecer sem mais delongas que a consciência/cognição/ conhecimento representa apenas uma parte da vida e das interações humanas. Os significados sociais e os sentidos pessoais não se reduzem ao plano cognitivo, na medida em que se formam por meio de 
situações e conteúdos que implicam emoção. "A linguagem aparece em nível individual cheia de sentido subjetivo, traduz emoções complexas no sujeito, gera novas emoções em seu constante trânsito pelos diferentes espaços representativos e experimentais do sujeito" (REY, 2003, p. 236). A emoção é uma condição permanente na definição de sujeito. Todo espaço de intervenção deve ser considerado espaço que mobiliza emoção e que por isso constitui espaço para geração de sentido: “(...) o emocionar-se é uma condição da atividade humana dentro do domínio da cultura, o que por sua vez se vê na gênese cultural das emoções humanas" (REY, 2003, p. 242).

Na medida em que pensamos em uma perspectiva de transformação social, devemos compreender que este ponto de invenção e criatividade aparecerá na contradição entre o social e o individual, no momento em que o indivíduo deixa de ser definido como sujeito "sujeitado", debatendo-se entre a sujeição social e suas opções individuais. Neste embate formam-se zonas de sentido, que sendo maleáveis, flexíveis e criativas apontam para a emancipação.

\begin{abstract}
O sujeito individual está inserido, de forma constante, em espaços da subjetividade social, e sua condição de sujeito atualiza-se permanentemente na tensão produzida a partir das contradições entre suas configurações subjetivas individuais e os sentidos subjetivos produzidos em seu trânsito pelas atividades compartilhadas nos diferentes espaços sociais. É neste processo que o conhecimento tem lugar, definindo assim, sua riqueza dinâmica (REY, 2011, p. 25).
\end{abstract}

No Brasil, a extensão rural encontra-se agora diante de uma grande multiplicidade de questões que tornam a epistemologia interdisciplinar da complexidade uma alternativa no campo político e social, e não apenas uma escolha caprichosa ou voluntariosa do pesquisador/extensionista. Um debate reaquecido no domínio das políticas públicas de ATER vem ao encontro de revisões paradigmáticas nas ciências sociais, especialmente a sociologia, com novos modos de definir o mundo rural; a discussão ambiental reforça as agendas do século XXI; os movimentos sociais do campo alcançam o sistema educacional brasileiro e uma nova formação dos jovens que vivem em contextos rurais advêm das escolas familiares agrícolas e dos projetos de educação do campo; as associações nãogovernamentais atuam fortemente e a agroecologia pontifica no cenário das transformações sociais, especialmente na região nordeste do Brasil; e ainda, uma expansão do ensino superior em direção ao interior tanto em cursos de graduação quanto em pós-graduação coloca um maior e expressivo número de pesquisadores em contato com a realidade agrária do Brasil. O campo de saberes, práticas e interações na extensão rural se amplia exponencialmente. Talvez não seja impróprio falar de uma ruralização dos conhecimentos. Agir no mundo rural pode ser hoje a oportunidade para acionar a reinstalação do dado sensível (LATOUR, 2013), recuperando a autonomia e a qualidade dos lugares, para resistir ao projeto de total unificação das sociedades e coletividades.

Nosso argumento é de que a nova realidade da extensão rural se potencializa, consoante o princípio da interdisciplinaridade, como cenário privilegiado no exercício de novas mentalidades e olhares construídos em muitas conversações. Os hábitos arraigados, os lugares comuns, os antigos vícios acadêmicos podem ser aí deconstruídos para a chegada de outros problemas, e quem sabe a realização de uma outra (des)ordem social. 


\section{ANOTAÇÕES DE UM DIÁRIO DE CAMPO E CERTAS CONVERSAS AO PÉ- DO-OUVIDO}

Quando a extensão rural se constitui no cenário da epistemologia da complexidade, ela contribui decisivamente para os outros saberes em jogo com sua longa experiência em atividades de campo, no sentido metodológico da expressão. Sejam quais forem as políticas, programas ou práticas em exercício, o fato é que a atividade extensionista estabelece inevitáveis círculos de interações sociais que favorecem a quebra do academicismo em tantas outras disciplinas e supera problemas de vinculação sujeito/objeto/sujeito que são comuns no âmbito disciplinar. Foi assim que, no exercício de uma interdisciplinaridade forte e complexa articulando agronomia, agroecologia, extensão rural, educação e psicossociologia, chegamos ao interior do estado do Amazonas, na tríplice fronteira entre Brasil, Colômbia e Peru. Falamos de uma inserção nossa em uma ação do Instituto de Desenvolvimento Agropecuário e Florestal Sustentável do Estado do Amazonas (IDAM) e uma comunidade de agricultores indígenas da etnia Tikuna, através de uma proposta de educação agrícola.

O local da experiência é a comunidade de Umariaçu, localizada em Tabatinga-AM. A comunidade apresenta uma divisão interna entre Umariaçu I e Umariaçu II, com hierarquias políticas próprias, possuindo cada uma delas um cacique escolhido por voto da população. O estudo se desenvolve em Umariaçu II, que está situada às margens do Rio Solimões, com apenas uma rota de acesso terrestre à comunidade de Umariaçu I. De acordo com o último Censo Demográfico, aproximadamente 342 mil autodeclarados indígenas habitam na Região Norte, dos quais 135.877 estão presentes no Amazonas e 5.368 são indígenas da etnia Tikuna residentes em Umariaçu, Tabatinga, com características sociais, culturais, econômicas e políticas peculiares (IBGE, 2012; PAGLIARO; AZEVEDO; SANTOS, 2005).

O município de Tabatinga tem uma população de aproximadamente 60000 habitantes e, segundo dados do IBGE, 70\% residem em áreas urbanas. A antiga aldeia, que se localiza a $8 \mathrm{~km}$ de distância do principal núcleo urbano de Tabatinga, passou por recentes transformações e possui hoje casas de alvenaria, energia elétrica e estrada asfaltada. Entre os indígenas há agricultores familiares e extrativistas.

No Amazonas, a principal agência de ATER é o Instituto de Desenvolvimento Agropecuário e Florestal Sustentável do Estado do Amazonas (IDAM), que se apresenta com a missão de prestar serviços de ATER aos agricultores familiares e produtores rurais do estado, mediante processos educativos e participativos, que Ihes assegurem sustentabilidade, cidadania e melhoria na qualidade de vida das populações rurais.

No município de Tabatinga/AM o IDAM atua realizando práticas de Demonstração de Métodos (DM), por meio de Unidades Demonstrativas (UD), Unidade de Observação (UO), realizando excursões, palestras, entre outras ações (BRANDÃO, 2014). A prática de extensão rural na Comunidade de Umariaçu ocorre em uma Unidade de Demonstração, onde os técnicos agrícolas interagem com os indígenas visando introduzir ferramentas e processos de mecanização nas áreas já ocupadas pela comunidade. Ali destacam-se o cultivo da banana e da mandioca.

Aqui apresentamos anotações de um diário de campo feitas quando o grupo de educadores e psicossociólogos iniciava sua inserção na equipe:

Chegamos em Umariaçu II num domingo pela manhã. Não tivemos nenhum problema para chegar até lá. As estradas bem 
pavimentadas permitiram o acesso sem dificuldades até o local da Unidade de Demonstração do IDAM. O trajeto durou aproximadamente meia hora. À medida que passávamos do núcleo urbano à aldeia, as casas rareavam e a paisagem se alterava, evidenciando-nos atividades agrícolas, organizadas em roças. Deixamos o carro e nos aproximamos das casas. $\mathrm{Na}$ primeira delas fomos recebidos por um grupo de crianças que pareciam ter entre três e sete anos de idade. Brincavam na varanda de uma casa rústica, de madeira, e nos receberam com muitos sorrisos. Estabelecemos uma comunicação por gestos, porque não falam e nem entendem a mesma língua dos pesquisadores e eles tão pouco falavam ou entendiam a língua deles. Ainda do lado de fora da casa, no terreiro, uma moça de aparentes vinte anos de idade banhava-se nua numa banheira adaptada de um galão de plástico. Acolheu-nos com um sorriso. Uma outra jovem, de aparentes quinze anos, varria a casa.

O limite entre a varanda e o cômodo central da casa, que se parecia com uma sala, estava franqueado ao olhar, mesmo que discreto. Nossa chegada não produziu nenhum movimento de reserva. Pudemos ver então, no meio da sala, uma televisão de última geração, transmitindo a cores e ao vivo uma corrida de automóveis da Fórmula I, narrada em português. A boa qualidade técnica do aparelho permitia um excelente nível de resolução da imagem, e como era uma TV de muitas polegadas, as imagens dos automóveis da corrida ocupavam um considerável espaço na sala. Prestando muita atenção na transmissão, havia um casal deitado na rede, com mais uma criança no colo. Soubemos por uma breve resposta, que o homem do casal entendia o português, embora não se expressasse fluentemente nessa língua.

Um contraste muito poderoso salta às vistas neste primeiro momento da incursão no campo: a simplicidade da nudez da jovem mulher, a evocar sentimentos de nostalgia quanto a um possível passado idílico, e a presença do equipamento tecnológico de última geração, transmitindo o circo da pós-modernidade. As duas cenas aparentemente paradoxais desestabilizam referências. $O$ antigo sonho da modernidade seria o de vestir aquela jovem e alterar a programação áudio-visual do grupo. Com nossas melhores intenções seríamos capazes de dizer que a nudez é incompatível com os pudores da civilização moderna, e a programação da TV representa uma modificação, para pior, dos códigos de dominação. Em nossa proposta, alternativamente, o que podemos ver aí é que a chegada dos bens de qualquer natureza não dependem de outra intenção que não a do próprio grupo. Tanto quanto os homens jovens que vivem em contextos urbanos considerados altamente desenvolvidos amam as corridas de automóveis, vibram, se encantam com as disputas, e acompanham interessados os pilotos dando voltas na pista, os jovens índios Tikuna também apreciam o esporte. Se olhamos com atenção o que se passa, e recorrendo à nossa arquitetura conceitual, podemos definir a cena pela transformação radical do sentido das ruralidades, com os processos psicossociais próprios de um ambiente altamente urbanizado, penetrando e formando novas zonas de sentidos, pessoais e coletivos, em ambientes antes correspondentes às descrições do rural, sem que isso aconteça segundo a suposta racionalidade da modernização. 
Não é de se estranhar que neste contexto haja grandes e importantes resistências na absorção das atividades demonstradas pela assistência técnica, se ela não leva em consideração o híbrido cultural, a multiplicidade de sentidos e a necessidade de compor identidades com os novos campos simbólicos e seus corolários afetivos.

\begin{abstract}
Seguindo em nossa jornada, naquele domingo, nos aproximamos de algumas outras casas, onde o mais notável era a audiência das corridas de automóveis transmitidas pelas televisões, sempre de telas grandes e bem sintonizadas. Assim como observamos nas cidades, os homens adultos jovens acompanhavam atentamente o programa. Ao interpelar os grupos de cada casa a respeito de suas atividades geradoras de renda, as respostas sempre apontavam a roça como principal ocupação. As roças são longe das casas e os homens vão até lá cumprindo grande marchas a pé.
\end{abstract}

Outro importante paradoxo a desafiar nosso entendimento e práticas: o valor que define as corridas de automóveis é a velocidade. A palavra de ordem nas transmissões televisivas é: Acelera! Se nos contextos urbanos entende-se que esta é realmente uma palavra de ordem que impacta o ritmo da vida nas cidades, no contexto dos índios Tikunas esta palavra incide e repercute em corpos lentos e talvez não atinjam mais do que a condição dos sonhos e da imaginação. Corpos lentos reverenciando heróis da velocidade.

Os técnicos agrícolas querem recomendar aos índios que plantam bananeiras que façam as covas com o auxílio de uma ferramenta potente. Eles questionam e se sentem perplexos diante da recomendação. Há muito tempo se sabe que as covas devem ser feitas com o galho de uma planta que tenha brotos na extremidade.

Eis um momento de grande desafio para o paradigma epistemológico no domínio de uma extensão rural interdisciplinar complexa: um limite no qual a racionalidade aberta se surpreende e se inclina. Para o pensamento típico da modernidade, nada mais improvável do que a existência de qualquer dado de realidade na recusa e na resistência - nada senão um sentido conservador de reprodução social.

Comecemos pela acusação de superstição. Uma leitura mesmo superficial da bibliografia etnográfica bastaria para convencer a qualquer investigador do abismo que existe entre, por um lado, a enorme colaboração dos coletivos chamados "tradicionais' para captar, situar, instituir, ritualizar "seres invisíveis" e, por outro, a defesa contínua das sociedades chamadas "modernas" contra esses seres, para impedir que tenham um assento garantido. De um lado, a instituição, de outro, a destituição (...) Para a investigadora, se entende, é difícil comparar coletivos tão diferentes: uns compreenderiam, em todo o sentido do verbo, aos seres invisíveis que estariam totalmente ausentes e seriam incompreensíveis entre os outros. De um lado existem por completo e de outro não existem de modo nenhum. (LATOUR, 2013. p. 183 - tradução livre das autoras). 
Contudo, complexamente se pode pensar que em uma perspectiva ecológica dos saberes seria possível traduzir tal conhecimento e levar para o laboratório a informação: que há de especial em um galho brotado que o torna diferente de uma ferramenta morta? Será que bioquimicamente a expressão da vida poderia representar um modo sutil de fertilização? Este já é um caminho mais estimulante, produtivo e criativo do que trabalhar com a hipótese única da resistência e introduzir mais e mais técnicas de persuasão, sem autocrítica ou movimento cognitivo algum.

Mais complexamente ainda, a discussão pode passar do terreno da epistemologia para o lado da ontologia, e o extensionista/pesquisador/psicólogo pode também deleitar-se com a poesia de um mundo onde os seres de ficção têm espessura ontológica e fazem parte da própria existência: entender que a presença viva dos ritos e mitos pode ser a maneira mais própria de lidar com uma dimensão psíquica que nas sociedades avançadas se transforma em doenças, sintomas e malestar. Provocar estas aberturas é o limite das nossas ações: o encontro entre os técnicos e os indígenas representa não apenas o confronto entre dois modos de saber, mas também o contraste entre dois modos de existência, sobre um pano de fundo político. E a conversa vai mudando de rumo por aqui.

\section{UM GESTO CELEBRATÓRIO PARA CONCLUIR}

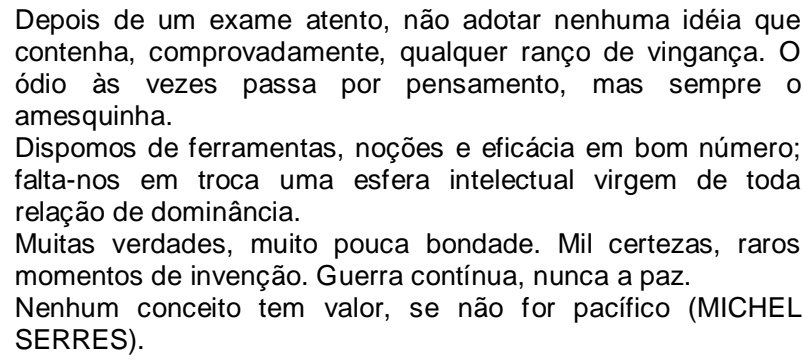

O que aciona nosso pensamento é a constatação de que este nosso século $X X I$, que parece ter começado ontem e que no entanto já vai longe, tem nos exigido trabalhar em ritmo intenso. A questão tantas vezes repetida no final do século passado, de que os paradigmas em uso estavam desmoronando por insuficiência ou arrogância já não é mais retórica ou literária: as instituições mais caras ao saber exibem fragilidades e sinais de decadência. A educação estertora!

Habitamos por isso um espaço de transição, posto que não podemos nos conformar com o cenário catastrófico. Em publicação anterior (MONTEIRO, 2006) tivemos a oportunidade de expressar nosso entendimento e sentimento frente às instabilidades próprias de uma etapa de transição nos domínios epistemológico e social:

Neste contexto desenha-se para nós, pesquisadores, um cenário de incertezas marcado, por um lado, pela decepção com as promessas da modernidade (seja por terem permanecido incompletas, seja por seu cumprimento ter conduzido a efeitos adversos) e, por outro lado, pelo fascínio com qualquer coisa ainda germinal que se anuncia (MONTEIRO, 2006, p. 30). 
Naquele momento, no mesmo trabalho, apontamos para alguns aspectos que considerava negativos e os que considerava positivos nas etapas de transição paradigmática. Entre os negativos, ganhou destaque a grande pulverização das referências que permitem situar um trabalho acadêmico no conjunto das produções de uma área, a intensa dispersão dos projetos políticos de ação/intervenção emergentes da atividade científica, e a diversidade, aparentemente inconciliável, dos sentido atribuídos às principais palavras-chave de cada domínio intelectual. Entre o que avaliava como positividades, foi apontada principalmente a enorme quantidade de aprendizagens possíveis no cruzamento das fronteiras que se multiplicavam então, abrindo-nos a possibilidades de configurações que amalgamam heranças e invenções, estabelecem outras formas de sociabilidade e nos colocam diante de realidades inusitadas.

Um ambiente instável, de riscos e expectativas, exige cruzar as fronteiras disciplinares entre domínios que carregam, cada qual, suas fortes hegemonias e aquele que cruza fronteiras corre duplo risco: ser considerado dissidente em seu campo de origem, e intruso no outro domínio. Para tanto, torna-se valorosa a existência de espaços de interação que atendam à chamada de Latour: "a novas guerras, novas pazes".

\section{REFERÊNCIAS}

BRANDÃO, E. A inclusão de técnicas científicas de plantio em comunidades indígenas (Projeto de Mestrado). Universidade Federal Rural do Rio de Janeiro, Rio de Janeiro, 2004.

FROEHLICH, J. M. Identidades e tradições reinventadas: o rural como tema e cenário. In CARNEIRO, M. J. Ruralidades contemporâneas: modos de viver e pensar o rural na sociedade brasileira. Rio de Janeiro: Mauad X. Faperj, 2012.

IBGE. Instituto Brasileiro de Geografia e Estatística. Censo demográfico 2010. Características gerais dos indígenas: resultado do universo. Rio de Janeiro, RJ: IBGE, 2010.

IBGE. Instituto Brasileiro de Geografia e Estatística. Os indígenas no censo demográfico 2010: primeiras considerações com base no quesito cor ou raça. Rio de Janeiro, RJ: IBGE, 2012.

LATOUR, B. Investigacíon sobre los modos de existencia. Buenos Aires: Argentina: Paidós, 2013.

MONTEIRO, R. C. Novas ruralidades e políticas públicas: proposições para um debate. In: J. M. FROEHLICH; V. DIESEL (Orgs.), Desenvolvimento rural: tendências e debates contemporâneos. Ijuí, RS: Edunijui, 2006.

MOREIRA, R. Extensão rural na contemporaneidade: cultura e política. CIMADEVILLA, G.; THORNTON, R. D.. La extension rural em debate. Buenos Aires, Argentina: Intituto Nacional de Tecnologia Agropecuária - INTA, 2003.

REY, F. G. Pesquisa qualitativa e subjetividade: os processos de construção da informação. São Paulo: Cengage Learning, 2010. 
REIS, E. J.; VIANA, J. M. M.; MONTEIRO, R. C. Habitar, transitar e atuar em fronteiras. Um desafio para a ressignificação da extensão rural. In G. CIMADEVILLA; R. D. THORNTON (Orgs.), Grises de la extensión, la comunicación y el desarrollo. Buenos Aires, Argentina: Intituto Nacional de Tecnologia Agropecuária INTA, 2008.

SANTOS, B. S. Renovar a teoria crítica e reinventar a emancipação social. São Paulo, Boitempo, 2007.

Cortez, 2010.

A gramática do tempo: para uma nova cultura política. São Paulo:

SPINK, P. Processos organizativos e ação política: as possibilidades emancipatórias do lugar. In: JACÓ VILELA, A. M.; SATO, L. Diálogos em psicologia social. Porto Alegre: Ed. Evangraf Ltda., 2007.

VASCONCELOS, E. M. Complexidade e pesquisa interdisciplinar. Petrópolis, Editora Vozes, 2004. 